\title{
Study of effect of myoinositol on menstrual irregularities and skin problems in polycystic ovarian syndrome cases
}

\author{
Monika Ranwa $^{1 *}$, Tripti Nagaria ${ }^{1}$, Jyoti Jaiswal ${ }^{1}$, Abhishek Arya ${ }^{2}$
}

\begin{abstract}
${ }^{1}$ Department of Obstetrics and Gynecology, BRAM Hospital, Raipur, Chattisgarh, India
${ }^{2}$ Department of Pediatrics, Indraprasth Apollo Hospital, New Delhi, India
\end{abstract}

Received: 09 May 2017

Accepted: 13 May 2017

\author{
*Correspondence: \\ Dr. Monika Ranwa, \\ E-mail: monikaranwa26@gmail.com
}

Copyright: () the author(s), publisher and licensee Medip Academy. This is an open-access article distributed under the terms of the Creative Commons Attribution Non-Commercial License, which permits unrestricted non-commercial use, distribution, and reproduction in any medium, provided the original work is properly cited.

\begin{abstract}
Background: Polycystic ovary syndrome (PCOS), first identified in 1935 as Stein-Leventhal syndrome, is a complex neuro-endocrine disorder affecting approximately $5 \%$ to $10 \%$ of women reproductive age. Typically PCOS is characterized by hyperandrogenism (extremely variable in its occurrence), chronic anovulation, polycystic ovaries at ultrasound evaluation and dermatological problems such as acne, hirsute and seborrhoea. PCOS is indeed the most common cause of female infertility.

Methods: This prospective interventional study was conducted during December 2012 to June 2013 in Department of Obstetrics and Gynaecology at Pt. Jawaharlal Nehru Memorial Medical College and Associated Dr. Bhim Rao Ambedkar Memorial Hospital, Raipur (C.G.) India, after obtaining permission of ethical committee of institute. All young girls and married women who attended GOPD of Department of Obstetrics and Gynaecology having polycystic ovarian syndrome as defined by Rotterdam Criteria were registered and screened for inclusion in the study. At the end of three months' data were compiled in MS-Excel and checked for its completeness and correctness then it was analysed suitable statistical test was applied and p-value $<0.05$ was considered statistically significant.

Results: Maximum no of cases were between 21 to 25 yrs age, youngest one was of 15 yrs and oldest one was of 33 yrs. $72 \%$ cases belonged to urban area and only $28 \%$ cases belonged to rural area. $94.67 \%$ of cases were presented with abnormal menstrual cycle. The most common menstrual abnormality was Oligomenorrhoea (43.66\%) followed by Oligomenorrhoea+Menorrhagia (21.13\%) than Amenorrhoea (19.71\%) and Hypomenorrhoea+Oligomenorrhoea (15.49\%). $42.7 \%$ cases had oily skin, $26.7 \%$ cases had hirsutism, $20 \%$ cases had acne and $9.3 \%$ cases had acanthosis nigricans. $74.65 \%$ cases $(53 / 75)$ were improved in their menstrual complaints; most common menstrual abnormality improved was Oligomenorrhoea+ Menorrhagia i.e. 88.67\% (13/15). Out of all cases of oligomenorrhoea $77.4 \%$ cases $(24 / 31)$ achieved regular menses. Out of all cases of oligomenorrhoea+ hypomenorrhoea $81.8 \% \%$ cases $(2 / 11)$ achieved regular menses.

Conclusions: Present study confirms that Myoinositol, an insulin sensitizer, by improving insulin signalling reduces insulin resistance and improves menstrual irregularities and skin problems of PCOS cases.
\end{abstract}

Keywords: Menstrual irregularity, Myoinositol, PCOS, Skin problems

\section{INTRODUCTION}

During the 2003 Rotterdam consensus meeting, it was agreed that PCOS should be diagnosed if at least two of the following three features are present: oligo/amenorrhoea, clinical or biochemical signs of androgen excess and PCO at ultrasound scan. Women are to be classified as NIH-PCOS if they present with oligo/amenorrhoea and clinical or biochemical hyperandrogenism. The current database allows for the 
assessment of PCOS according to Rotterdam criteria in women presenting with ovarian dysfunction. ${ }^{1}$

Polycystic ovary syndrome (PCOS), first identified in 1935 as Stein-Leventhal syndrome, is a complex neuroendocrine disorder affecting approximately $5 \%$ to $10 \%$ of women reproductive age. Typically, PCOS is characterized by hyperandrogenism (extremely variable in its occurrence), chronic anovulation, polycystic ovaries at ultrasound evaluation and dermatological problems such as acne, hirsute and seborrhoea. ${ }^{2}$ PCOS is indeed the most common cause of female infertility.

The primary defect in PCOS appears to be an exaggerated androgen synthesis and secretion particularly by ovarian theca cells; insulin resistance and obesity may act as triggers of this primary defect, explaining the frequent association of PCOS with obesity and insulin resistance. ${ }^{3}$ Upon careful examination of ovaries from PCOS women, small islands of hyperthecosis were usually present. This morphological change was more extensive in insulin-resistant PCOS women, suggesting that hyperinsulinemia had an impact on ovarian morphology as well as on function.

Hyperinsulinaemia, the consequence of insulin resistance, stimulates both ovarian (mainly) and adrenal androgen secretion and suppresses sex hormone-binding globulin synthesis from the liver, thereby resulting in an increase in free, biologically active androgens. This excess in local ovarian androgen production causes a premature follicular atresia and anovulation along with other clinical manifestations of hyperandrogenism such as hirsutism, acne, seborrhoea and alopecia.

Some studies have suggested that impairment in the insulin pathway could be due to a defect in the inositolphosphoglycans (IPGs) second messenger. IPGs are known to have a role in activating enzymes that control glucose metabolism. In PCOS women, a defect in tissue availability or altered metabolism of Inositol or IPGs mediators may contribute to insulin resistance. Phosphatidylinositol 3-kinase (PI 3 kinase) is a key messenger enzyme responsible for glucose transport so as to utilize glucose and liberating energy. Inositol acts as a precursor for the synthesis of phosphatidylinositol. Inositol plays an imported role in production and activation of PI3 kinase. Deficient level of inositol is found in PCOS and deficiency of inositol alters activity of PI3 kinase. Reduced activity of PI3 kinase reduces translocation of GLUT-4 thereby causing hyperglycemia this brings about altered insulin signalling causing hyperinsulinaemia and thus insulin resistance. Insulin resistance thus is responsible for PCOS..$^{4-7}$

At the same time, urinary clearance of inositol is significantly higher in PCOS women resulting in low plasma concentration of inositol in these women.
Management options include lifestyle interventions such as diet and exercise, hormonal therapy include oral contraceptive, Anti-androgen therapy, insulin sensitizers etc. Insulin sensitizing compounds, such as metformin, pioglitazone, troglitazone have been proposed as a putative treatment to solve the hyperinsulinemia induced dysfunction of ovarian response to endogenous gonadotropins in order to improve ovulation, spontaneous pregnancy, menstrual cyclicity and hyperandrogenemia. However, commonly used insulin sensitizing drugs, like metformin, can induce gastrointestinal side effects, possibly resulting in reduced patient compliance. ${ }^{7-9}$

Myoinositol is a new insulin sensitizer; it is one of nine different types of inositol and can be found naturally in many foods items such as fruits, nuts and beans. Myoinositol is classified as member of vitamin B complex (often referred to as vitamin B8). It is a naturally occurring substance produced in the human body. Serum concentrations are high during fetal life and later on falls during certain conditions like periconceptional periods, polycystic ovarian syndrome.

Epimerization of the six hydroxyl groups of Inositol leads to the formation of up to nine stereoisomers, including Myoinositol and D chiro Inositol, both stereoisomers were used as insulin sensitizer drugs in the treatment of PCOS cases. D chiro Inositol is synthesized by an epimerase that converts Myoinositol into D chiro Inositol, with each tissue having its own particular conversion rate, likely to be specific needs for the two different molecules. Myoinositol is an important constituent of the follicular microenvironment, playing a key role in the nuclear and cytoplasmic oocyte's development. Furthermore, higher concentrations of myoinositol in human follicular fluid provide a marker of good-quality oocytes. ${ }^{10}$

Considering the fact that inositol deficiency is the basic pathophysiology for PCOS, inositol supplementation can correct the menstrual irregularities and skin problems. On these bases, the present study was planned to evaluate the effects of Myoinositol administration on menstrual irregularities and skin problems in cases of PCOS.

\section{METHODS}

This prospective interventional study was conducted during December 2012 to June 2013 in Department of Obstetrics and Gynaecology at Pt. Jawaharlal Nehru Memorial Medical College and Associated Dr. Bhim Rao Ambedkar Memorial Hospital, Raipur (C.G.) India, after obtaining permission of ethical committee of institute.

All young girls and married women who attended GOPD of Department of Obstetrics and Gynaecology having polycystic ovarian syndrome as defined by Rotterdam Criteria were registered and screened for inclusion in the study. ${ }^{11}$ 


\section{Exclusion criteria}

- Congenital adrenal hyperplasia

- Idiopathic hyperandrogenism or Hirsuitism

- Pelvic inflammatory disease or any adnexal pathology

- Diagnosed or suspected malignant neoplastic disease

- Hyperprolactinemia

- Adrenal tumour

- Liver disorder

- Renal disorder

- Bleeding disorder

- Thyroid disorder

- Signs or symptoms of mental illness

- If treatment taken for the same complaint in last 6 months.

All the cases were explained about the study protocol and the cases who gave consent were further investigated. Blood investigations were done to obtain baseline information. Other specific investigation as per requirement are assessed on day- 2 of menstrual cycle in cases with oligomenorrhoea/ regular menses, while in amenorrheic women hormonal profile was evaluated on any random day. Insulin sensitivity was computed as glucose to insulin ratio.

Transabdominal/Transvaginal Ultrasonography was performed to note the uterine volume, ovarian volume, if possible follicle count, endometrial thickness (millimeters) and to rule out any pathology. These women were given Tab Myoinositol $2 \mathrm{gm}$ daily (1 gm twice a day) continuously for 3 months. Follow up was done monthly till 3 months in every visit cases were evaluated. At the end of three months' data were compiled in MS-Excel and checked for its completeness and correctness then it was analysed suitable statistical test was applied and p-value $<0.05$ was considered statistically significant.

\section{RESULTS}

Maximum no of cases was between 21 to 25 yrs age, youngest one was of $15 \mathrm{yrs}$ and oldest one was of $33 \mathrm{yrs}$. (Table 1).

Table 1: Distribution of cases according to age.

\begin{tabular}{|lll|}
\hline Age in years & Total $(\mathbf{N}=75)$ & \\
\hline $15-20$ & No. & $\%$ \\
\hline $21-25$ & 23 & 30.6 \\
\hline $26-30$ & 33 & 44 \\
\hline$>30$ & 17 & 22.7 \\
\hline Total & 2 & 2.7 \\
\hline Mean+SD & 75 & 100 \\
\hline
\end{tabular}

$72 \%$ cases belonged to urban area and only $28 \%$ cases belonged to rural area (Table 2).
Table 2: Distribution of cases according to residence.

\begin{tabular}{|lll|}
\hline Residence & Total $(\mathbf{N}=75)$ & \\
\hline Rural & No & \% \\
\hline Urban & 21 & 28 \\
\hline Total & 54 & 72 \\
\hline
\end{tabular}

Table 3: Distribution of cases according to the menstrual abnormality.

\begin{tabular}{|lll|}
\hline Menstrual cycle & No & $\%$ \\
\hline Abnormal & 71 & 94 \\
\hline Normal & 4 & 6 \\
\hline
\end{tabular}

$94.67 \%$ of cases were presented with abnormal menstrual cycle. The most common menstrual abnormality was Oligomenorrhoea (43.66\%) followed by Oligomenorrhoea+Menorrhagia (21.13\%) than Amenorrhoea (19.71\%) and Hypomenorrhoea+ Oligomenorrhoea $(15.49 \%$ ) (Table 3, 4).

Table 4: Distribution of cases according to the type of menstrual abnormality.

\begin{tabular}{|lll|}
\hline Menstrual abnormality & \multicolumn{2}{l|}{ No. of cases $(\mathbf{N}=71)$} \\
\hline Oligomenorrhoea & No. & \% \\
\hline Amenorrhoea & 31 & 43.66 \\
\hline $\begin{array}{l}\text { Hypomenorrhoea+ } \\
\text { oligomenorrhoea }\end{array}$ & 14 & 19.71 \\
\hline $\begin{array}{l}\text { Oligomenorrhoea+ } \\
\text { menorrhagia }\end{array}$ & 11 & 15.49 \\
\hline Total & 15 & 21.13 \\
\hline
\end{tabular}

Table 5: Distribution of cases according to skin problems.

\begin{tabular}{|c|c|c|}
\hline \multirow{2}{*}{ Skin problem } & \multicolumn{2}{|c|}{ Total $(\mathbf{N}=75)$} \\
\hline & No. & $\%$ \\
\hline Oily skin & 32 & 42.7 \\
\hline Acne & 15 & 20 \\
\hline Moderate & 11 & 73.3 \\
\hline Severe & 04 & 26.7 \\
\hline Hirsuitism & 20 & 26.7 \\
\hline FGS 1-4 & 04 & 20 \\
\hline FGS 5-8 & 11 & 55 \\
\hline FGS $>8$ & 05 & 25 \\
\hline Mean FGS & \multicolumn{2}{|c|}{$7.55 \pm 3.70$} \\
\hline Acanthosis nigricans & 7 & 9.3 \\
\hline Nape of the neck & 4 & 57.1 \\
\hline Axilla & 2 & 28.6 \\
\hline Perineal & 1 & 14.3 \\
\hline Under breast & 1 & 14.3 \\
\hline Virilization & 0 & 0 \\
\hline Total & 75 & 100 \\
\hline
\end{tabular}

42.7\% cases had oily skin, $26.7 \%$ cases had hirsutism, $20 \%$ cases had acne and $9.3 \%$ cases had acanthosis 
nigricans (Table 5). $74.65 \%$ cases (53/75) were improved in their menstrual complaints; most common menstrual abnormality improved was Oligomenorrhoea+ Menorrhagia i.e. $88.67 \%$ (13/15) (Table 6).

Table 6: Distribution of cases according to improvement in menstrual abnormality after treatment.

\begin{tabular}{|llll|} 
Menstrual abnormality & $\begin{array}{l}\text { Before treatment } \\
\text { (No. of patients) }\end{array}$ & No. of cases improved & \% Improvement \\
\hline Oligomenorrhoea & 31 & 24 & 77.4 \\
\hline Amenorrhoea & 14 & 7 & 50 \\
\hline Oligomenorrhoea+ Hypomenorrhoea & 11 & 9 & 81.8 \\
\hline Oligomenorrhoea+ Menorrhagia & 15 & 13 & 88.67 \\
\hline Total & 71 & 53 & 74.65 \\
\hline
\end{tabular}

Table 7: Distribution of cases having oligomenorrhoea according to improvement after treatment.

\begin{tabular}{|c|c|c|c|}
\hline \multirow{2}{*}{ Total no. of oligomenorrhoea patient $\mathrm{N}=31$} & \multicolumn{3}{|c|}{ Time taken for the start of spontaneous menses } \\
\hline & 1 month & 2 month & 3 month \\
\hline \multirow{3}{*}{ No. of patients $(\%)$} & $21(67.7 \%)$ & $18(58 \%)$ & $18(58 \%)$ \\
\hline & 0 & $6(19.3 \%)$ & $6(19.3 \%)$ \\
\hline & 0 & 0 & $4(12.9 \%)^{*}$ \\
\hline Progressive no of patients who achieved spontaneous menses $(\%)$ & $21(67.7 \%)$ & $24(77.4 \%) * * *$ & $28(90.3 \%)^{* *}$ \\
\hline No. of patients not responded $(\%)$ & \multicolumn{3}{|l|}{$7(22.5 \%)$} \\
\hline
\end{tabular}

Table 8: Distribution of cases having amenorrhoea according to improvement after treatment.

\begin{tabular}{|c|c|c|c|}
\hline \multirow{2}{*}{ Total no. of amenorrhoea patient $\mathrm{N}=14$} & \multicolumn{3}{|c|}{ Time taken for the start of spontaneous menses } \\
\hline & 1 month & 2 month & 3 month \\
\hline \multirow{3}{*}{ No. of patients $(\%)$} & $5(35.7 \%)$ & $5(35.7 \%)$ & $5(35.7 \%)$ \\
\hline & 0 & $2(14.2 \%)$ & $2(14.2 \%)$ \\
\hline & 0 & 0 & 0 \\
\hline Progressive no of patients who achieved spontaneous menses $(\%)$ & $5(35.7 \%)$ & $7(50 \%)$ & $7(50 \%)$ \\
\hline No. of patients not responded $(\%)$ & $7(50 \%)$ & & \\
\hline
\end{tabular}

Table 9: Distribution of cases having oligomenorrhoea+hypomenorrhoea according to improvement after treatment.

\begin{tabular}{|c|c|c|c|}
\hline \multirow{2}{*}{$\begin{array}{l}\text { Total no. of patient of oligomenorrhoea+hypomenorrhoea } \\
N=11\end{array}$} & \multicolumn{3}{|c|}{ Time taken for the start of spontaneous menses } \\
\hline & 1 month & 2 month & 3 month \\
\hline \multirow{3}{*}{ No. of patients (\%) } & $7(63.6 \%)$ & $7(63.6 \%)$ & $7(63.6 \%)$ \\
\hline & 0 & $2(18.1 \%)$ & $2(18.1 \%)$ \\
\hline & 0 & 0 & 0 \\
\hline Progressive no of patients who achieved spontaneous menses (\%) & $7(63.6 \%)$ & $9(81.8 \%)$ & $9(81.8 \%)$ \\
\hline No. of patients not responded (\%) & $2(18.1 \%)$ & & \\
\hline
\end{tabular}

Out of all cases of oligomenorrhoea $77.4 \%$ cases $(24 / 31)$ achieved regular menses (Table 7). Out of all cases of amenorrhoea $50 \%$ cases $(7 / 14)$ achieved regular menses (Table 8).

Out of all cases of oligomenorrhoea+hypomenorrhoea $81.8 \% \%$ cases (2/11) achieved regular menses (Table 9).
Out of all cases of oligomenorrhoea+ Menorrhagia $86.7 \%$ cases (13/15) achieved regular menses (Table 10).

Oily skin and acne were improved in $34.4 \%(11 / 31)$ and $33.3 \%(5 / 15)$ cases respectively (Table 11). No significant change was observed in modified Ferriman Gallway score (Table 12). 
Table 10: Distribution of cases having oligomenorrhoea+menorrhagia according to improvement after treatment.

\begin{tabular}{|l|lll|}
\hline Total no. of patient Oligomenorrhoea+Menorrhagia N=15 & \multicolumn{4}{l|}{ Time taken for the start of spontaneous menses } \\
\hline & $\mathbf{1}$ month & $\mathbf{2}$ month & $\mathbf{3}$ month \\
\hline No. of patients (\%) & $9(60 \%)$ & $8(53.3 \%)$ & $8(53.3 \%)$ \\
& 0 & $4(26.7 \%)$ & $4(26.7 \%)$ \\
\hline Progressive no of patients who achieved spontaneous menses (\%) & 9 & 0 & $1(6 \%)$ \\
\hline No. of patients not responded (\%) & $2(60 \%)$ & $12(80 \%)$ & $13(86.7 \%)$ \\
\hline
\end{tabular}

*This case had previous cycle at interval of 3-4 months and this time she achieved menses at interval of 2 months so she was considered as improved.

Table 11: Effect of myoinositol on skin problems.

\begin{tabular}{|llll|}
\begin{tabular}{|l} 
Skin \\
problem
\end{tabular} & $\begin{array}{l}\text { Pre- } \\
\text { treatment }\end{array}$ & $\begin{array}{l}\text { No. of } \\
\text { cases not } \\
\text { improved }\end{array}$ & $\begin{array}{l}\% \\
\text { improvement }\end{array}$ \\
\hline Oily skin & 32 & 21 & 34.4 \\
\hline Acne & 15 & 10 & 33.3 \\
\hline Moderate & 11 & 7 & 36.4 \\
\hline Severe & 04 & 3 & 25 \\
\hline Hirsuitism & 20 & 20 & \\
\hline mFGS $1-4$ & 04 & 6 & \\
\hline mFGS $4-8$ & 11 & 10 & \\
\hline m FGS $>8$ & 05 & 04 & \\
\hline $\begin{array}{l}\text { Acanthosis } \\
\text { nigricans }\end{array}$ & 7 & 7 & \\
\hline
\end{tabular}

Table 12: Effect of myoinositol on modified Ferriman Gallway score.

\begin{tabular}{|llll} 
mFGS & $\begin{array}{l}\text { Pre- } \\
\text { treatment } \\
\text { (Mean) }\end{array}$ & $\begin{array}{l}\text { After } \\
\text { treatment } \\
\text { (Mean) }\end{array}$ & $\begin{array}{l}\mathrm{p} \\
\text { value }\end{array}$ \\
Mean mFGS & $7.55 \pm 3.70$ & $7.2 \pm 3.05$ & 0.355 \\
\hline
\end{tabular}

\section{DISCUSSION}

In our study with 2 gm Myoinositol supplementation 53 out of $71(74.65 \%)$ cases achieved regular menstrual cycles during therapy. Out of 71 cases, 31 cases $(43.66 \%)$ had oligomenorrhoea, 15 cases $(21.13 \%)$ had oligomenorrhoea with menorrhagia, 14 cases $(19.71 \%)$ had amenorrhoea and rest 11 cases $(15.49 \%)$ were suffering from oligomenorrhoea along with hypomenorrhoea. Nearly two third of oligomenorrheic cases i.e. $77.4 \%(24 / 31)$ achieved spontaneous onset of menses and then subsequent regular menses during the course of therapy. Half of cases i.e. 50\% (7/14) of all amenorrheic cases started spontaneous menstrual cycle.

$81.8 \%(9 / 11)$ cases of oligomenorrhoea with hypomenorrhoea had improved in menstrual bleeding pattern and $88.67 \%(13 / 15)$ of cases who had having oligomenorrhoea with menorrhagia improved. Our results are similar as observed by Papaleo et al after a mean of $34.6+5.5$ days of Myoinositol $2 \mathrm{gm}$ with folic acid $200 \mu \mathrm{g}$ administration, twenty-two out of the $25(88 \%)$ patients restored at least one spontaneous menstrual cycle, of whom 18 (72\%) maintained monthly menstruations during the follow-up period. ${ }^{12}$ Present data confirms what has been previously reported by Gerli et al in terms of recovery of menstrual cyclicity in most of the patients after daily Myoinositol $2 \mathrm{gm}$ with folic acid $200 \mu \mathrm{g}$ administration for 4 months. ${ }^{13}$ Genazzani et al also observed that all patients under Myoinositol $2 \mathrm{gm}$ with folic acid $200 \mu \mathrm{g}$ administration reported menstrual cycles during the 12 weeks of treatment, in particular all five amenorrheic PCOS subjects reported eumenorrhea or oligomenorrhea after the treatment interval while no changes occurred in the patients treated with folic acid alone. ${ }^{14}$ Similarly Ventuerella et al and Le donne et al had shown significant improvement in menstrual abnormality in their studies in 2012. ${ }^{15,16}$ Present results are much better than observed by Lin L et al, in 55 cases of PCOS after 24 weeks therapy with $1.5 \mathrm{gm}$ Metformin out of these 55 , only $60.7 \%$ cases had spontaneous regular menses. ${ }^{17}$

Raffone et al reported that insulin sentitiser agents, both metformin and Myoinositol, can be considered first-line treatment in most patients with PCOS, for restoring normal menstrual cycles. ${ }^{18}$

According to Rotterdam criteria to diagnose PCOS hyperandrogenism is one of the criteria to diagnose PCOS which may be defined by presence of acne, hirsutism, oily skin etc. Hyperandrogenism is the key feature of PCOS, resulting primarily from excess androgen production in the ovaries and, to a lesser extent, in the adrenals.

The primary mechanism driving increased ovarian androgen production in PCOS include increased LH stimulation resulting from abnormal LH secretory dynamics and increased bioactivity, and hyperinsulinemia due to insulin resistance, which potentiates the action of LH and is worsened by obesity. Hyperinsulinemia results in increased ovarian androgen biosynthesis in vivo and in vitro and decreased sex hormone-binding globulin (SHBG) synthesis from the liver, leading to increased bioavailability of free androgens. No one definite mechanism explains the moderate adrenal androgen 
excess in PCOS. Overproduction of either testosterone or testosterone precursors leads to exaggerated testosterone action in target tissues such as the skin. The most frequent dermatologic manifestation of androgen excess is hirsutism. Other cutaneous manifestations of androgen excess include acne, acanthosis nigricans and androgenic alopecia.

So, any measure which reduces high level of Insulin will result in reduction in androgen level also. Myoinositol is a potent insulin sensitizer and by improving insulin sensitivity it reduces serum insulin level, thereby reduces androgens level and improves clinical sign and symptom of hyperandrogenism like acne, hirsutism, oily skin etc.

In present study, we observed the effect of Myoinositol on skin changes and it was found that $34.4 \%$ i.e. (11/31) cases had improvement in their oily skin, $33.3 \%(5 / 15)$ cases had improvement in acne. All the cases who had hirsutism, continued to have same state at the end of therapy, only two cases showed improvement in Ferriman Gallwey score one who had FGS between 4-8 and other who had FGS $>8$ had improvement at the end of therapy. Mean Ferriman Gallwey score was reduced from
$7.55 \pm 3.70$ to $7.3 \pm 3.05$ at the end of therapy (nonsignificant $\mathrm{p}=0.355$ ). Genazzani et al had also documented no significant change in Ferriman Gallwey score $(22.7 \pm 1.4$ to $18 \pm 0.8$ after 8 weeks therapy of Myoinositol $2 \mathrm{gm}$ with folic acid $200 \mu \mathrm{g}) .{ }^{14}$ Various other studies have however documented a significant reduction in Ferriman Gallwey score after $2 \mathrm{gm}$ or $4 \mathrm{gm}$ Myoinositol with folic acid $200 \mu \mathrm{g}$ or OCP for $12 \mathrm{wks}$ to 12 months (Table 13). ${ }^{16,19-21}$

Minozzi et al found significant reduction from $9.7 \pm 3.6$ to $6.7 \pm 1.9(\mathrm{p}<0.05)$ in Ferriman Gallwey score after 12 months therapy with $4 \mathrm{gm}$ Myoinositol plus $400 \mu \mathrm{g}$ folic acid in combination with OCP (EE $30 \mu \mathrm{g} /$ gestodene 75 $\mathrm{mg}$ ) and also shown significant reduction from 10.2+3.4 to $8.1+2.3$ in group receiving OCP (EE $30 \mu \mathrm{g} /$ gestodene $75 \mathrm{mg}$ ) alone but FG score was significantly lower in $\mathrm{OCP}+\mathrm{MYO}+\mathrm{Folic}$ acid group compared with OCP group $(p<0.001) .{ }^{19}$ Zacche et al found significant reduction from $11.4 \pm 3.2$ to $9.94 \pm 2.8$ in Ferriman Gallwey score after 6 months therapy with $2 \mathrm{gm}$ Myoinositol $(\mathrm{p}<0.05)$ and Le donne et al also observed significant reduction in Ferriman Gallwey score after 12 wks therapy with $4 \mathrm{gm}$ Myoinositol+Diet+metformin $(\mathrm{p}<0.05){ }^{16,20}$

Table 13: Effect of myoinositol on Ferriman Gallaway score.

\begin{tabular}{|c|c|c|c|c|c|c|c|}
\hline $\begin{array}{l}\text { Year of } \\
\text { study }\end{array}$ & Author & $\begin{array}{l}\text { Dose of } \\
\text { myo inositol }\end{array}$ & $\begin{array}{l}\text { No. of } \\
\text { cases }\end{array}$ & $\begin{array}{l}\text { Duration of } \\
\text { therapy }\end{array}$ & $\begin{array}{l}\text { Pre- } \\
\text { treatment } \\
\text { level }\end{array}$ & $\begin{array}{l}\text { Post- } \\
\text { treatment } \\
\text { level }\end{array}$ & $\begin{array}{l}\mathrm{p} \\
\text { value }\end{array}$ \\
\hline 2007 & Le donne et al & 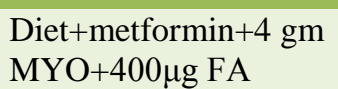 & 9 & $12 \mathrm{wks}$ & --- & -- & 0.05 \\
\hline 2009 & Zacche et al & $2 \mathrm{gm} \mathrm{MYO}+400 \mu \mathrm{g} F A$ & 50 & $6 \mathrm{mts}$ & $11.4 \pm 3.2$ & $9.94 \pm 2.8$ & 0.03 \\
\hline \multirow[t]{2}{*}{2011} & \multirow{2}{*}{ Minozzi et al } & $\begin{array}{l}4 \mathrm{gm} \mathrm{MYO}+400 \mu \mathrm{g} \\
\mathrm{FA}+\mathrm{OCP}\end{array}$ & 80 & \multirow[t]{2}{*}{$12 \mathrm{mts}$} & $9.7 \pm 3.6$ & $6.7 \pm 1.9$ & $<0.001$ \\
\hline & & OCP & 75 & & $10.2+3.4$ & $8.1+2.3$ & $<0.001$ \\
\hline 2012 & Genazzani et al & $2 \mathrm{gm} \mathrm{MYO}+200 \mu \mathrm{g}$ & 42 & 8 wks & $22.7 \pm 1.4$ & $18 \pm 0.8$ & NS \\
\hline 2014 & present study & 2 gm Myoinositol & 75 & $12 \mathrm{wks}$ & $7.55 \pm 3.70$ & $7.3 \pm 3.05$ & 0.355 \\
\hline
\end{tabular}

Myoinositol, a novel insulin sensitizer, by ameliorating the performance of insulin signal and consequently reducing insulin level, represent a simple and safe treatment. Myoinositol improves insulin sensitivity thereby reduces androgen levels as a consequence Myoinositol supplementation benefits cutaneous disorder of hyperandrogenism. In previous studies conducted for effect of metformin in PCOS, significant reduction in modified Ferriman Gallwey score from 7.9+.9 to $6.1+0.9$ $(\mathrm{p}<005)$ after 12 weeks was observed by Cho LW et al in comparison to Pioglitazone and Orlistat. ${ }^{22}$ Talieh kazerooni et al showed significant reduction in modified Ferriman Gallwey score from $8.4+2.8$ to $7.3+1.9$ (p $<0.005)$ after 12 weeks with metformin and more significant reduction was observed when metformin was combined with Simvastatin $(p=0.001) .^{23}$ These other comparable therapies for hyperandrogenism like metformin and OCP are present since a long time but due to GIT side effects of metformin it is less tolerated and OCP is also less acceptable among young girls. So Myoinositol is considered a simple and safe treatment. As our study was conducted for a very short period and during that short period of therapy significant reduction could not be observed.

\section{CONCLUSION}

Polycystic ovary syndrome (PCOS) is a disorder of chronically abnormal ovarian function and hyperandrogenism, affecting 5-10\% of female population in reproductive age. Present study confirms that Myoinositol, an insulin sensitizer, by improving insulin signalling reduces insulin resistance and improves menstrual irregularities and skin problems of PCOS 
cases. Current study conclude that 2 gm/day Myoinositol administration for 3 months improves insulin sensitivity thereby results in correction of menstrual irregularities and skin problems among polycystic ovarian syndrome cases.

\section{ACKNOWLEDGMENTS}

Authors would like to thank study participants for their cooperation in providing the necessary information. Great thanks go also to all those who were involved in this study directly or indirectly for their support.

Funding: No funding sources

Conflict of interest: None declared

Ethical approval: The study was approved by the Institutional Ethics Committee

\section{REFERENCES}

1. Rotterdam ESHRE/ASRM-Sponsored PCOS Consensus Workshop Group. Revised 2003 consensus on diagnostic criteria and long-term PCOS according to the Rotterdam consensus criteria and long-term health risks related to polycystic ovary syndrome. Fertil Steril. 2004;81:19-25.

2. Ehrmann DA. Polycystic ovary syndrome. N Engl J Med. 2005;352:1223-36.

3. Nelson VL, Qin KN, Rosenfield RL, Wood JR, Penning TM, Legro RS et al. The biochemical basis for increased testosterone production in theca cells propagated from patients with polycystic ovary syndrome. J Clin Endocrinol Metab. 2001;86:592533.

4. Rosenbaum D, Haber RS, Dunaif A. Insulin resistance in polycystic ovary syndrome: decreased expression of GLUT-4 glucose transporters in adipocytes. Am J Physiol. 1993;264:197-202.

5. Kennington AS, Hill CR, Craig J, Bogardus C, Raz I, Ortmeyer HK et al. Low urinary chiro-inositol excretion in non-insulin-dependent diabetes mellitus. N Engl J Med. 1990;323:373-8.

6. Lord JM, Flight IH, Norman RJ. Insulin-sensitising drugs (metformin, troglitazone, rosiglitazone, pioglitazone, D-chiroinositol) for polycystic ovary syndrome. Cochrane Database Syst Rev. 2003;(3):CD003053.

7. Nestler JE, Jakubowicz DJ, Reamer P, Gunn RD, Allan G. Ovulatory and metaboliceffects of D-chiroinositol in the polycystic ovary syndrome. N Engl J Med. 1999;340:1314-20.

8. Papaleo E, Unfer V, Baillargeon JP, De Santis L, Fusi F, Brigante $\mathrm{C}$ et al. Myo-inositol in patients with polycystic ovary syndrome: a novel method for ovulation induction. Gynecol Endocrinol. 2007;23:700-3.

9. Cohen P. The twentieth century struggle to decipher insulin signalling. Nat Rev Mol Cell Biol. 2006;7:867-73.
10. Baillargeon JP, Nestler JE, Ostlund RE, Apridonidze $\mathrm{T}$, DiamantiKandarakis E. Greek hyperinsulinemic women, with or without polycystic ovary syndrome, display altered inositols metabolism. Hum Reprod. 2008;23:1439-46.

11. Eshre TR, ASRM-Sponsored PCOS Consensus Workshop Group. Revised 2003 consensus on diagnostic criteria and long-term health risks related to polycystic ovary syndrome (PCOS). Hum Reprod. 2004;19:41-7.

12. Papaleo E, Unfer V, Baillargeon JP, De Santis L, Fusi F, Brigante $\mathrm{C}$ et al. Myoinositol in patients with polycystic ovary syndrome: a novel method for ovulation induction. Gynecol Endocrinol. 2007;23:700-3.

13. Gerli S, Papaleo E, Ferrari A, Di Renzo GC. Randomized, double blind placebo-controlled trial: effects of myo-inositol on ovarian function and metabolic factors in women with PCOS. Eur Rev Med Pharmacol Sci. 2007;11:347-54.

14. Genazzani AD, Lanzoni C, Ricchieri F, Jasonni Vm. Myo-inositol administration positively affects hyperinsulinemia and hormonal parameters in overweight patients with polycystic ovary syndrome. Gynecol Endocrinol. 2008;24:139-44.

15. Venturella R, Mocciaro R, De Trana E, D'Alessandro P, Morelli M, Zullo F. Assessment of the modification of the clinical, endocrinal and metabolic profile of patients with PCOS syndrome treated with myo-inositol. Minerva Ginecol. 2012;64(3):239-43.

16. Le Donne M, Alibrandi A, Giarrusso R, Lo Monaco I, Muraca U. Diet, metformin and inositol in overweight and obese women with polycystic ovary syndrome: effects on body composition. Minerva Ginecol. 2012;64(1):23-9.

17. Liao L, Tian YJ, Zhao JJ, Xin Y, Xing HY, Dong JJ. Metformin versus metformin plus rosiglitazone in women with polycystic ovary syndrome. Chin Med J. 2011;124(5):714-8.

18. Raffone E, Rizzo P, Benedetto V. Insulin sensitiser agents alone and in cotreatment with r-FSH for ovulation induction in PCOS women. Gynecol Endocrinol. 2010;26(4):275-80.

19. Minozzi M, Costantino D, Guaraldi C, Unfer V. The effect of a combination therapy with myo-inositol and a combined oral contraceptive pill versus a combined oral contraceptive pill alone on metabolic, endocrine, and clinical parameters in polycystic ovary syndrome. Gynecol Endocrinol 2011;27(11):920-4.

20. Zacche MM, Caputo L, Filippis S, Zacche G, Dindelli M, Ferrari A. Efficacy of myo-inositol in the treatment of cutaneous disorders in young women with polycystic ovary syndrome. Gynecol Endocrinol 2009;25: 508-13.

21. Genazzani AD, Prati A, Santagni S, Ricchieri F, Chierchia E, Rattighieri E. Differential insulin response to myo-inositol administration in obese 
polycystic ovary syndrome patients. Gynecol Endocrinol. 2012;28(12):969-73.

22. Cho LW, Kilpatrick, Keevil BG, Coday AM, Atkin SL. Effect of metformin, orlistat and pioglitazone treatment on mean insulin resistance and its biological variability in polycystic ovarion syndrome. Clinical Endocrinol. 2009;70:233-7.

23. Kazerooni T, Shojaei-Baghini A, Dehbashi S, Asadi N, Ghaffarpasand F, Kazerooni Y. Effects of metformin plus simvastatin on polycystic ovary syndrome: a prospective, randomized, double-blind, placebo-controlled study; Fertil Steril. 2010;94(6):2208-13.

Cite this article as: Ranwa M, Nagaria T, Jaiswal J, Arya A. Study of effect of myoinositol on menstrual irregularities and skin problems in polycystic ovarian syndrome cases. Int J Reprod Contracept Obstet Gynecol 2017;6:2310-7. 